\title{
Simulation of Transport Phenomena around the Raceway Zone in the Blast Furnace with and without Pulverized Coal Injection
}

\author{
Hideyuki AOKI, Hiroshi NOGAMI," ') Hideo TSUGE, ${ }^{2)}$ Takatoshi MIURA and Takeshi FURUKAWA ${ }^{3)}$
}

Department of Biochemistry and Engineering, Tohoku University, Aza-Aoba, Aramaki, Aoba-ku, Sendai, Miyagi-ken, 980 Japan. $\quad 1$ ) Institute for Advanced Materials Processing, Tohoku University, Katahira, Aoba-ku, Sendai, Miyagi-ken, 980 Japan. $\quad 2)$ Graduate School, Tohoku University, Aza-Aoba, Aramaki, Aoba-ku, Sendai, Miyagi-ken, 980 Japan.

3) Steel Research Center, NKK Corporation, Minamiwatarida-cho, Kawasaki-ku, Kawasaki, Kanagawa-ken, 210 Japan.

(Received on December 14, 1992; accepted in final form on February 25, 1993)

\begin{abstract}
A two-dimensional mathematical model is developed to describe transport phenomena in a packed bed of coke in front of blast furnace tuyere with and without pulverized coal injection ( $\mathrm{PCl})$. The model consists of two sub-models, one is pulverized coal (PC) combustion model in the blowpipe where the turbulent fluctuation in the gas phase is considered and the other is combustion model in the packed bed of coke. In this model coke particles in the raceway are treated as a continuous phase and both phases of gas and coke particles are calculated by using the Eulerian approach.

This model is applied to practical operating conditions. When PC is injected into tuyere, more oxygen is consumed and higher temperature rise appears at the region closer to tuyere tip in the raceway and lower temperature is represented in the coke bed than those of all coke operation. Residence time of PC particles in the blowpipe is quite short, so its burn-off in the blowpipe is very low and the PC particles mainly burn in the raceway cavity. The burn-off of PC particle increases with the volatile matter content, but some particles reach to inner wall of tuyere when high volatile coal is used.
\end{abstract}

KEY WORDS: mathematical model; blast furnace; pulverized coal injection; raceway; combustion.

\section{Introduction}

The operation with pulverized coal injection (PCI) into a blast furnace tuyere is employed for reducing the coke feed rate. It is known that operating conditions, such as kinds of coal, pulverized coal (PC) diameter and injection method of PC influence the combustion behavior in the raceway zone. When the feed rate of $\mathrm{PC}$ increases, the unburned char accumulated in the furnace causes the permeability through the coke bed to decrease. It follows that the stable state of operation cannot be achieved. Few experimental attempts such as the recent literature ${ }^{1)}$ are made to examine the PCI method and the limit of PCI rate in the blast furnace. In order to predict the unburned char production at PCI operation and clarify the limit of PCI rate, it is important to analyze the heat and mass transfer phenomena around the raceway zone. It is however too difficult to obtain the accurate information in the blast furnace especially in the raceway zone.

Mathematical model provides a useful and powerful tool for investigating the effect of uncertain factors on the combustion characteristics of pulverized coal. Concerning the mathematical models, several studies are carried out on the one-dimensional analysis of coke combustion $^{2)}$ and PC combustion, ${ }^{3)}$ and total models analyze the phenomena of gas flow, reaction and heat transfer. ${ }^{4-6)}$ The drastic simplifying assumptions are used in the previous models especially near the raceway zone. The accurate mathematical model is furthermore required to evaluate the effect of a large amount of PC and use of rich oxygen on the blast furnace operation.

In this study we develop the simulation model to predict the transport phenomena near the raceway zone where the effect of volatile matter content in coal on combustion behavior and of the operating condition with and without PCI on the shape of raceway and distributions of temperature and gas species concentration are examined.

\section{Model Formulation}

This model consists of two sub-models, one is PC combustion model in the blowpipe and the other is combustion model in the packed bed of coke. The blowpipe model calculation is carried out on axisymmetrical coordinate system and the coke bed model is on rectangular two-dimensional coordinate system where the calculated results of the blowpipe model are used as inlet conditions. The motion of PC particles in both sub-models is solved by Lagrangian approach and coke particles in the raceway are treated as a kind of fluid and the flow field of the coke bed is calculated by using two-phase-flow approach. 


\subsection{Governing Equations}

The general form of conservation equations of mass, momentum and energy for gas and packed bed of coke is

$$
\begin{aligned}
& \frac{\partial}{\partial x}\left(\varepsilon_{i} \rho_{i} U_{i} \phi_{i}\right)+\frac{1}{\zeta} \frac{\partial}{\partial y}\left(\zeta \varepsilon_{i} \rho_{i} V_{i} \phi_{i}\right) \\
& =\frac{\partial}{\partial x}\left(\Gamma_{\phi_{i}} \frac{\partial \phi_{i}}{\partial x}\right)+\frac{1}{\zeta} \frac{\partial}{\partial y}\left(\zeta \Gamma_{\phi_{i}} \frac{\partial \phi_{i}}{\partial y}\right)+S_{\phi_{i}}+S_{d \phi}
\end{aligned}
$$

where the general variable $\phi_{i}(i=$ gas, bed) is unity for the continuity equation and otherwise represents one of the dependent variables as follows: the gas velocity components $\left(U_{g}, V_{g}\right)$, the velocity components of coke particles $\left(U_{b}, V_{b}\right)$, turbulent energy $\left(k_{t}\right)$, eddy dissipation rate $\left(\varepsilon_{t}\right)$, enthalpy $\left(h_{g}, h_{b}\right)$ and mass fraction of chemical species $\left(m_{j}: j=\right.$ volatile matter, $\mathrm{O}_{2}, \mathrm{~N}_{2}, \mathrm{CO}_{2}, \mathrm{H}_{2} \mathrm{O}, \mathrm{CO}$, $\mathrm{H}_{2}$ ). $\zeta$ is taken to be $y$ on axisymmetrical coordinate and to be 1 on two-dimensional one. $\Gamma_{\phi_{i}}$ is the exchange coefficient, $S_{\phi_{i}}$ is the source term in the gas and solid phases and $S_{d \phi}$ is the source term between PC particle and the gas phase whose coupling is estimated using the PSI-cell method. ${ }^{16)}$ Values of $\Gamma_{\phi_{i}}$ and $S_{\phi_{i}}$ for the coke bed model are shown in Table 1. Solution method for the blowpipe model is the same as our previous work. ${ }^{7)}$ The partial differential Eq. (1) are calculated simultaneously with the method of Patankar. ${ }^{8)}$

\subsection{Pulverized Coal Combustion Model in the Blowpipe}

The combustion of $\mathrm{PC}$ is a complicated process because of involving turbulent flow, chemical reaction, and heat and mass transfer. Simplification of the governing equations is achieved by adopting the following assumptions

1) Particle is spherical.

2) There is no break-up or coalescence of particle.

3) Particle is initially composed of raw coal, char and ash.

4) Raw coal is composed of volatile matter and char. Char is considered to be pure carbon.

5) Particle temperature is uniform within the sphere.

Using above assumptions, we have carried out the prediction of the combustion characteristics in the one-dimensional laminar-flow furnace ${ }^{9)}$ and the twodimensional turbulent-flow furnace, ${ }^{10)}$ and confirmed the performance of the model.

\subsubsection{Chemical Reactions}

A PC particle injected into the blowpipe is heated by the radiation from surrounding gas and wall and the convective heat transfer, then it releases the volatile matter. Coal devolatilization is modeled by parallel, first-order reactions ${ }^{10)}$ as follows

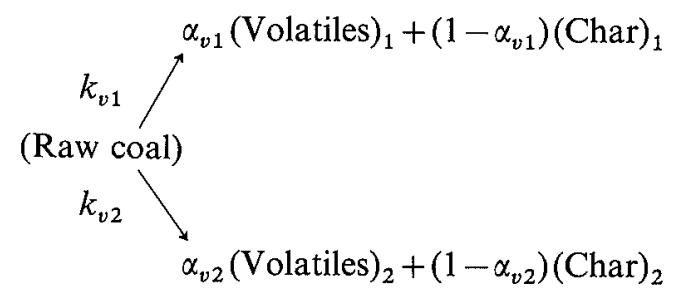

The rate constants $k_{v 1}$ and $k_{v 2}$ have Arrhenius form, and

\begin{tabular}{|c|c|c|c|c|c|}
\hline$i$ & & $\phi$ & $\Gamma$ & & $S_{\phi_{i}}$ \\
\hline \multirow[t]{7}{*}{ Gas } & & 1 (mass) & 0 & & 0 \\
\hline & & $U_{g}$ & $\mu_{e f f}$ & & $\frac{\partial}{\partial x}\left(\mu_{e f f} \frac{\partial U_{g}}{\partial x}\right)+\frac{\partial}{\partial y}\left(\mu_{e f f} \frac{\partial V_{g}}{\partial x}\right)-\varepsilon_{g} \frac{\partial P}{\partial x}-S_{b u}$ \\
\hline & & $V_{g}$ & $\mu_{e f f}$ & & $\frac{\partial}{\partial x}\left(\mu_{e f f} \frac{\partial U_{g}}{\partial y}\right)+\frac{\partial}{\partial y}\left(\mu_{e f f} \frac{\partial V_{g}}{\partial y}\right)-\varepsilon_{g} \frac{\partial P}{\partial y}-S_{b v}$ \\
\hline & & $m_{j}$ & $\rho_{g} D_{e}$ & & $R_{j}$ \\
\hline & & $h_{g}$ & $\frac{\lambda_{e g}}{C_{P g}}$ & & $Q_{h}+\sum R_{j} Q_{r j}$ \\
\hline & & $k_{i}$ & $\frac{\mu_{e f f}}{\sigma_{k}}$ & & $G-\rho_{g} \varepsilon_{t}$ \\
\hline & & $\varepsilon_{t}$ & $\frac{\mu_{e f f}}{\sigma_{\varepsilon}}$ & & $\frac{\varepsilon_{t}}{k_{t}}\left(C_{1} G-C_{2} \rho_{g} \varepsilon_{t}\right)$ \\
\hline \multirow[t]{6}{*}{ Bed } & & 1 (mass) & 0 & & 0 \\
\hline & & $U_{b}$ & $\mu_{b}$ & & $\frac{\partial}{\partial x}\left(\mu_{b} \frac{\partial U_{b}}{\partial x}\right)+\frac{\partial}{\partial y}\left(\mu_{b} \frac{\partial V_{b}}{\partial x}\right)-\varepsilon_{b} \frac{\partial P}{\partial x}+S_{b u}+S_{p u}$ \\
\hline & & $V_{b}$ & $\mu_{b}$ & & $\frac{\partial}{\partial x}\left(\mu_{b} \frac{\partial U_{b}}{\partial y}\right)+\frac{\partial}{\partial y}\left(\mu_{b} \frac{\partial V_{b}}{\partial y}\right)-\varepsilon_{b} \frac{\partial P}{\partial y}+S_{b v}-S_{p v}$ \\
\hline & & $h_{b}$ & $\frac{\lambda_{e b}}{C_{p b}}$ & & $-Q_{h}+\Sigma R_{j} Q_{r j}$ \\
\hline & $C_{1}$ & $C_{2}$ & $\sigma_{k}$ & $\sigma_{\varepsilon}$ & $\sigma_{m}$ \\
\hline & 1.44 & 1.92 & 0.90 & 1.22 & 0.90 \\
\hline
\end{tabular}

Table 1. Source terms in the coke bed model.

$G=\mu_{e f f}\left[2\left\{\left(\frac{\partial U_{g}}{\partial x}\right)^{2}+\left(\frac{\partial V_{g}}{\partial y}\right)^{2}\right\}+\left(\frac{\partial U_{g}}{\partial y}+\frac{\partial V_{g}}{\partial x}\right)^{2}\right]$ 
are such that $k_{v 2}$ has a higher activation energy, so that the reaction in $k_{v 2}$ path occurs at a high temperature. The kinetic parameters are taken from Ubhayakar et al. ${ }^{11)}$ and mass-stoichiometric factors $\alpha_{v 1}$ and $\alpha_{v 2}$ from Burgess et al. ${ }^{12)}$

Concerning the heterogeneous reactions of char both in the blowpipe and in the raceway of coke bed, the overall rate for char-oxygen reaction at the external surface area depends on a combination of chemical reaction and diffusion of oxygen to the particle surface. The rate coefficients are taken from Field's ${ }^{13)}$ experimental data.

The rate of change in mass of raw coal $W_{R C}$, volatile matter $W_{V M}$ and char $W_{C H}$ can be obtained from

$$
\begin{gathered}
\frac{d w_{R C}}{d t}=-\left(k_{v 1}+k_{v 2}\right) w_{R C} \\
\frac{d w_{V M}}{d t}=\left(\alpha_{v 1} k_{v 1}+\alpha_{v 2} k_{v 2}\right) w_{R C} \\
\frac{d w_{C H}}{d t}=-\left(\frac{d w_{R C}}{d t}-\frac{d w_{V M}}{d t}\right)-A_{p} k_{s} m_{\mathrm{O}_{2}}
\end{gathered}
$$

The kinetic parameters used in the devolatilization scheme and char heterogeneous reaction are summarized in Table 2.

\subsubsection{Particle Heating}

The heat convection, radiation, heat release by chemical reaction and latent heat of devolatilization are considered in the particle heating process. Particle temperature can be given from the heat balance as

$$
\begin{aligned}
w_{p} C_{p} \frac{d T_{p}}{d t}= & A_{p} h_{c p}\left(T_{g}-T_{p}\right)+\xi_{v} Q_{v}+\xi_{c} Q_{c} \\
& +\frac{\kappa_{p}}{\rho_{N_{p}}}\left(I_{T}-I_{p}\right)-L_{v} \ldots \ldots \ldots \ldots
\end{aligned}
$$

where $\xi_{v}$ and $\xi_{c}$ represent the fraction of the combustion heat of volatile matter and char which is transferred to the particle, respectively. Although these values depend on practical operating conditions such as temperatures of particle and surrounding gas, $\xi_{v}=0.3$ and $\xi_{c}=0.5$ based on the analysis of the laminar-flow furnace $^{9)}$ for

\begin{tabular}{|c|c|c|c|}
\hline \multicolumn{4}{|c|}{$k=A_{i} \exp \left(E_{i} / T_{p}\right)$} \\
\hline \multicolumn{4}{|c|}{ Devolatilization $^{11)}$} \\
\hline Path & $\alpha_{v i}[-]$ & $A_{i}\left[\mathrm{~s}^{-1}\right]$ & $E_{i}[\mathrm{~K}]$ \\
\hline 1 & V.M. $/ 100$ & $3.7 \times 10^{5}$ & 18000 \\
\hline 2 & $2 \times \alpha_{v 1}$ & $1.46 \times 10^{13}$ & 30200 \\
\hline \multicolumn{4}{|c|}{ Char combustion $^{13)}$} \\
\hline & ${ }^{2} \mathrm{~s}$ atm] & $E[\mathbf{K}]$ & \\
\hline & & 18000 & $T_{p} \leqq 1273 \mathrm{~K}$ \\
\hline-4 & $\times 10^{-3} T_{p}$ & 0 & $T_{p}>1273 \mathrm{~K}$ \\
\hline
\end{tabular}
simplification of calculation. The latent heat of devolatilization $L_{v}$ is assumed to be $626.2 \mathrm{~kJ} / \mathrm{kg}$ deter-

Table 2. Kinetic parameters for the combustion of a single coal particle.

V.M.: volatile matter content (wt \%-d.a.f.) mined from the experimental data of Baum et al. ${ }^{14)}$

\subsubsection{Particle Motion}

The particle velocity in the blowpipe and the raceway can be calculated from the equation of motion of particle which can be written as

$$
\begin{array}{ll}
x \text {-direction: } \quad \frac{d u_{p}}{d t}=3 \mu_{g} C_{D p} \frac{R e_{p}}{4 \rho_{p} d_{p}^{2}}\left(U_{g}-u_{p}\right) \ldots \\
r \text { - or } y \text {-direction : } \frac{d v_{p}}{d t}=3 \mu_{g} C_{D p} \frac{R e_{p}}{4 \rho_{p} d_{p}^{2}}\left(V_{g}-v_{p}\right) \ldots
\end{array}
$$

where $U_{g}$ and $V_{g}$ are the instantaneous gas velocity obtained by adding the mean value from Eq. (1) and turbulent velocity fluctuation chosen randomly from an isotropic Gaussian distribution with standard deviation of $(2 k / 3)^{0.5}$. The drag coefficient $C_{D p}$ is a function of particle Reynolds number and taken from Clift et al. ${ }^{15)}$

$$
R e_{p}=\frac{\rho_{g} d_{p}\left|U_{g}-U_{p}\right|}{\mu_{g}}
$$

\subsubsection{Combustion Behavior of Pulverized Coal}

The ordinary differential Eqs. (3) to (8) are integrated simultaneously using Runge-Kutta-Gill method. Particles are divided into 10 classes in the initial injection point and 10 classes in the initial particle diameter by $10 \mu \mathrm{m}$ based on measured particle diameter distribution (from 10 to $100 \mu \mathrm{m}$ ) and trajectory is calculated for 3 particles for each class. The particle interacts with gas flow field producing source terms $S_{d \phi}$ of mass, momentum and enthalpy in Eq. (1). ${ }^{16)}$

\subsection{Combustion Model in the Coke Bed}

\subsubsection{Chemical Reactions}

In the coke bed model seven reactions are considered and are shown in Table 3.

Combustion of volatiles [1]

The single-step overall reaction is assumed in the combustion process of volatiles. The chemical reaction is considered to occur rapidly and thus the overall rate is controlled by turbulent diffusion process where the eddy-dissipation model ${ }^{17)}$ is utilized as

$$
R_{f u}=-C_{R}\left(\rho_{g} \frac{\varepsilon_{t}}{k_{t}}\right) \min \left(m_{f u}, \frac{m_{o x}}{C_{S}}\right)
$$

\section{$\mathrm{CO}$ oxidation $[2]$}

The reaction rate of $\mathrm{CO}$ oxidation is taken to be smaller value between that estimated by the eddy-dissipation model and the chemical reaction rate measured by Howard $^{18)}$ as

Table 3. Reactions employed in the coke bed model.

\begin{tabular}{ll|ll}
\hline \multicolumn{2}{c|}{ Homogeneous } & \multicolumn{2}{|c}{ Heterogeneous } \\
\hline V.M. $+\alpha \mathrm{O}_{2} \rightarrow$ Products & {$[1]$} & $\mathrm{C}+\frac{1}{2} \mathrm{O}_{2} \rightarrow \mathrm{CO}$ & {$[4]$} \\
$\mathrm{CO}+\frac{1}{2} \mathrm{O}_{2} \rightarrow \mathrm{CO}_{2}$ & {$[2]$} & $\mathrm{C}+\mathrm{O}_{2} \rightarrow \mathrm{CO}_{2}$ & {$[5]$} \\
$\mathrm{H}_{2}+\frac{1}{2} \mathrm{O}_{2} \rightarrow \mathrm{H}_{2} \mathrm{O}$ & {$[3]$} & $\mathrm{C}+\mathrm{CO}_{2} \rightarrow \mathrm{CO}_{2}$ & {$[6]$} \\
& & $\mathrm{C}+\mathrm{H}_{2} \mathrm{O} \rightarrow \mathrm{CO}+\mathrm{H}_{2}$ & {$[7]$} \\
\hline
\end{tabular}




$$
\begin{aligned}
\frac{d[\mathrm{CO}]}{d t}= & 1.3 \times 10^{11}[\mathrm{CO}]\left[\mathrm{O}_{2}\right]^{0.5}\left[\mathrm{H}_{2} \mathrm{O}\right]^{0.5} \\
& \times \exp \left(-\frac{15100}{T_{g}}\right) \varepsilon_{g}
\end{aligned}
$$

\section{Hydrogen oxidation [3]}

It is reported by $\mathrm{He}$ et $a l .^{3)}$ that hydrogen is not found at the atmosphere of oxygen concentration less than $5 \mathrm{~mol} \%$. For the region at the local oxygen concentration greater than $5 \mathrm{~mol} \%$ the rate is determined from eddy-dissipation model while no oxidation reaction on hydrogen occurs for that less than $5 \mathrm{~mol} \%$.

\section{Char heterogeneous reactions [4] to [7]}

Char heterogeneous reactions are assumed to be first-order irreversible with respect to the gas concentration to react and controlled by a combination of chemical reaction and diffusion of reacting gas within the micropore and to the boundary layer of a particle surface. The overall rate constant is evaluated as

$$
k_{i}=\frac{A_{b}}{1 / k_{d j}+1 /\left(\eta_{i} k_{c i}\right)}
$$

Especially for the coke oxidation reactions, [4] and [5], the experimental data are reported by Field ${ }^{19)}$ for the overall carbon consumption, i.e. the sum of reactions [4] and [5]. The ratio $\mathrm{CO} / \mathrm{CO}_{2}$ at the coke surface is then given by Arthur's data. ${ }^{21)}$ The rate constants of heterogeneous reactions [4] to [7] are shown in Table 4.

\subsubsection{Mass Transfer Rate Estimation}

The effective exchange coefficient between gas and coke particles is evaluated from Ligny's correlation ${ }^{22)}$ in terms of Peclet, Reynolds and Schmidt numbers as follows

$$
\frac{1}{P e}=\frac{C_{d 1}}{R e \cdot S c}+\frac{C_{d 2}}{1+C_{d 3} /(\operatorname{Re} \cdot S c)}
$$

where the magnitude of $C_{d 1}, C_{d 2}$ and $C_{d 3}$ shown in Table 5 are given by fitting the measured data of Gunn and Pryce $^{23)}$ to the above equation.

\subsubsection{Heat Transfer Rate Estimation}

The effective thermal conductivity of packed bed of coke is estimated using Kunii-Smith's equation. ${ }^{24)}$ The convective heat transfer coefficient is obtained from

Table 4. Kinetic coefficients for heterogeneous reactions.

\begin{tabular}{ccr}
\hline Reaction & Coefficient & Ref. \\
\hline$[4,5]$ & $7260 \exp \left(-18000 / T_{m}\right) R T_{g}$ & $19)$ \\
{$[6]$} & $8.31 \times 10^{9}\left(\rho_{b} / A_{b}\right) \exp \left(-30200 / T_{m}\right)$ & $20)$ \\
{$[7]$} & $13.4\left(\rho_{b} / A_{b}\right) T_{m} \exp \left(-17300 / T_{m}\right)$ & $2)$ \\
\hline
\end{tabular}

$T_{m}:$ mean temperature $(\mathrm{K})$.

Table 5. Coefficients in Eq. (13).

\begin{tabular}{lccr}
\hline & $C_{d 1}$ & $C_{d 2}$ & \multicolumn{1}{c}{$C_{d 3}$} \\
\hline Longitudinal & 0.239 & 0.523 & 3.21 \\
Radial & 0.270 & 0.100 & 13.94 \\
\hline
\end{tabular}

Ranz's equation: ${ }^{25}$

$$
\frac{d_{b} h_{c b}}{\lambda_{g}}=2.0+0.6(9 R e)^{0.5} \operatorname{Pr}^{0.33}
$$

The rate of convective heat transfer is thus calculated from

$$
Q_{h}=A_{b} h_{c b}\left(T_{g}-T_{b}\right)
$$

The effective thermal conductivity of gas phase passing through the packed bed of coke is given by analogy between heat transfer and mass transfer. All of the heat of homogeneous reactions is given to the gas phase, while all of the heat of heterogeneous reactions at the coke particle surface is given to the solid phase.

\subsection{Raceway Boundary}

It is necessary for obtaining the combustion characteristics in the raceway to evaluate the particle moving region in the coke bed. The following conditions are assumed for the particle moving region.

1) the vertical powder pressure of coke is negative,

2) the horizontal interaction force between the gas and solid is larger than the critical value of static friction force between the coke particles,

3) the voidage within $\mathrm{CV}$ is larger than that at minimum fluidization condition.

The critical value of static friction force between the coke particles in the condition 2) is the product of vertical powder pressure in $\mathrm{CV}$ and the internal friction coefficient (tangent of the internal friction angle).

\subsubsection{Source Term Arising from Interaction between Gas and Solid Phase}

The momentum exchange rate between gas and solid phase is calculated by the source terms $S_{b u}$ and $S_{b v}$. When the voidage is less than 0.8 in $\mathrm{CV}, S_{b u}$ is evaluated as the pressure drop due to the friction between gas and coke particles described by the Ergun's equation ${ }^{26)}$ as

$$
\begin{aligned}
S_{b u}= & \left(150 \frac{\left(1-\varepsilon_{g}\right)^{2} \mu_{g}}{\varepsilon_{g} \psi_{c}^{2} d_{b}^{2}}+1.75 \frac{\left|U_{g}-U_{b}\right|\left(1-\varepsilon_{g}\right) \rho_{g}}{\psi_{c} d_{b}}\right) \\
& \times \varepsilon_{g}\left(U_{g}-U_{b}\right) \ldots \ldots \ldots \ldots \ldots \ldots \ldots \ldots \ldots \ldots \ldots \ldots \ldots \ldots \ldots \ldots \ldots \ldots \ldots \ldots \ldots \ldots \ldots \ldots \ldots \ldots \ldots \ldots \ldots \ldots \ldots
\end{aligned}
$$

On the other hand, when the voidage is greater than 0.8 , the expression of $S_{b u}$ is based on the drag force of fluid acting on a single particle as

$$
S_{b u}=\frac{3}{4} C_{D} \frac{\left|U_{g}-U_{b}\right| \varepsilon_{g} \rho_{g}\left(1-\varepsilon_{g}\right)}{d_{b}} f\left(\varepsilon_{g}\right) \varepsilon_{g}\left(U_{g}-U_{b}\right)
$$

where

$$
\begin{array}{ll}
C_{D_{b}}=\frac{24}{R e_{p}}\left\{1+0.15\left(R e_{p}\right)^{0.687}\right\} & R e_{p}<1000 \\
C_{D_{b}}=0.44 & R e_{p} \geq 1000
\end{array}
$$

where $f\left(\varepsilon_{g}\right)$ evaluates the effect of the presence of other particles investigated by $\mathrm{Wen}$ and $\mathrm{Yu}^{27)}$ and acts as a correction to the usual Stokes law for free fall of a single particle. The expression for the source term in the vertical direction $\mathrm{S}_{b v}$ is the same as that in the horizontal direction. 


$$
f\left(\varepsilon_{g}\right)=\varepsilon_{g}^{-2.65}
$$

2.4.2. Source Term Arising from Gravitational Force

The powder pressure in coke bed is needed for determining the raceway boundary and the momentum generation caused by the gravitational force. The powder pressure affected by the gas flow is estimated by integrating modified Janssen's equation ${ }^{28)}$ including the term $F$ due to gas-solid interaction force from the bed surface to the depth of $\mathrm{CV}$.

$$
\frac{d P_{v}}{d h_{d}}=\rho_{b} g-F-\frac{4}{D_{T}} \mu_{w} K_{a} P_{v}
$$

where $K_{a}$ is a ratio of the horizontal powder pressure to the vertical one at dynamic state and evaluated from Rankine's equation as

$$
K_{a}=\frac{1-\sin \theta_{i}}{1+\sin \theta_{i}}
$$

At the region of voidage greater than that of minimum fluidization, the powder pressure, which is not transported downward, is a deduction of particles weight within the volume from the interaction force between gas and solid.

\section{Result and Discussion}

\subsection{Flow Patterns in Cold Model Experiment of Race- way}

The validity of the raceway model is examined in experimental cold raceways. The schematic diagram of experimental apparatus is shown in Fig. 1. The thin rectangular container packing particles has $19 \mathrm{~mm}$ thickness, $300 \mathrm{~mm}$ width and $600 \mathrm{~mm}$ height. The transparent two-dimensional bed enables particles motion to be observed during the tests. The tuyere, from which air supplied to the bed, is a $2 \mathrm{~mm}$ by $19 \mathrm{~mm}$ rectangular slit and is placed at $70 \mathrm{~mm}$ above the container bottom plane. Glass beads of $1 \mathrm{~mm} / 2 \mathrm{~mm}$ diameter and $2500 \mathrm{~kg} / \mathrm{m}^{3}$ density are used as the packing material and packed in $450 \mathrm{~mm}$ height at the initial state.

Figure 2 shows the comparison of calculated and observed raceway shapes and the particle flow patterns.

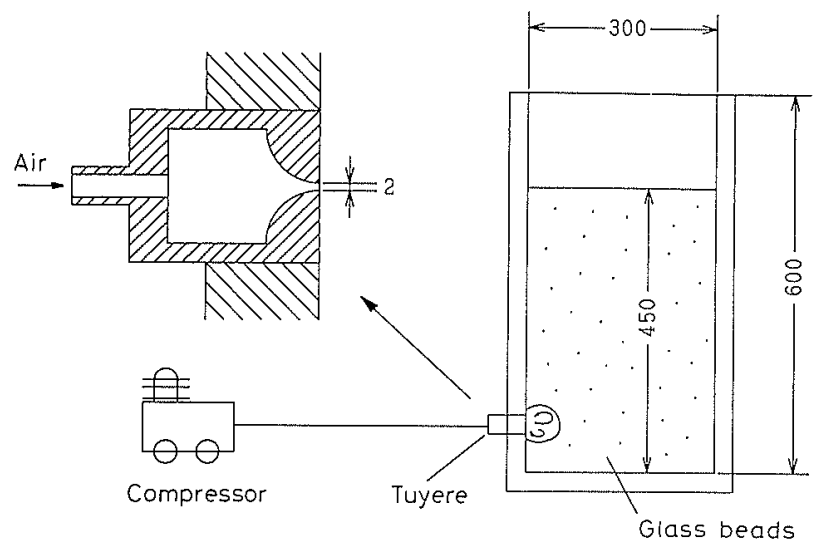

Fig. 1. Schematic diagram of experimental apparatus.
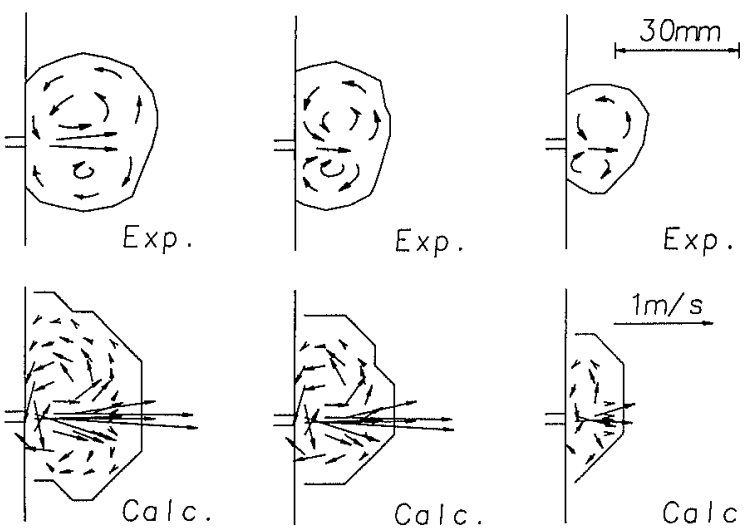

\section{(a) $d_{b}=1 \mathrm{~mm} \quad$ (b) $d_{b}=2 \mathrm{~mm} \quad$ (c) $d_{b}=1 \mathrm{~mm}$ $F R=12 \mathrm{Nm}^{3} / \mathrm{hr} \quad E R=12 \mathrm{Nm}^{3} / \mathrm{hr} \quad F R=8.4 \mathrm{Nm}^{3} / \mathrm{hr}$ FR: Volume flow rate of gas}

Fig. 2. Comparison of calculated raceway shape and particle flow pattern with the experimental results.

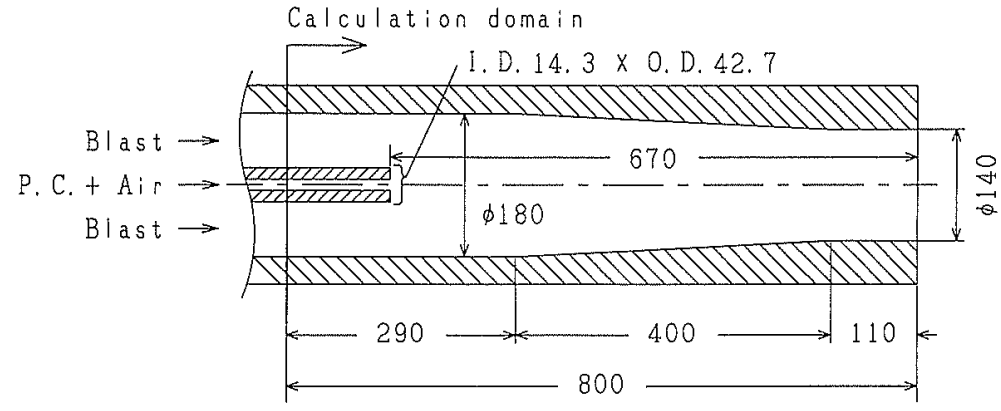

Fig. 3.

\begin{tabular}{|c|c|c|c|c|c|c|c|}
\hline \multirow[b]{2}{*}{ Coal } & \multicolumn{2}{|c|}{$\begin{array}{c}\text { Proximate analysis } \\
\text { [wt } \% \text {-d.b. }]\end{array}$} & \multicolumn{4}{|c|}{$\begin{array}{l}\text { Ultimate analysis } \\
\text { [wt \%-d.a.f.] }\end{array}$} & \multirow{2}{*}{$\begin{array}{c}\text { Calorific value } \\
{[\mathrm{MJ} / \mathrm{kg}]}\end{array}$} \\
\hline & V.M. & Ash & $\mathrm{C}$ & $\mathrm{H}$ & $\mathrm{N}$ & $S$ & \\
\hline Saraji & 19.5 & 9.0 & 89.2 & 4.7 & 2.0 & 0.7 & 32.9 \\
\hline Witbank & 34.3 & 7.2 & 83.6 & 5.1 & 2.2 & 0.7 & 31.4 \\
\hline Taiheiyo & 44.6 & 15.6 & 77.5 & 6.5 & 1.0 & 0.2 & 26.4 \\
\hline
\end{tabular}

Calculation domain for the blowpipe model.

Table 6. Analysis of the coal samples. 
In the experimental raceway a solid line and arrrows indicate the raceway boundary and directions of particles motion, respectively. In the calculated raceway a solid

Table 7. Calculation condition for the blowpipe model.

\begin{tabular}{llc}
\hline Blast : & Feed rate & $4.241 \mathrm{~kg} / \mathrm{s}$ \\
& Inlet velocity & $188 \mathrm{~m} / \mathrm{s}$ \\
& Temperature & $1450 \mathrm{~K}$ \\
& Pressure & $386 \mathrm{kPa}$ \\
& Composition oxygen & $24.7 \mathrm{wt} \%$ \\
& & $3.1 \mathrm{wt} \%$ \\
\hline \multirow{2}{*}{ Pulverized coal : } & Foisture & $0.165 \mathrm{~kg} / \mathrm{s}$ \\
& Teed rate & $300 \mathrm{~K}$ \\
\hline \multirow{2}{*}{ P.C. air : } & Feed rate & $0.0186 \mathrm{~kg} / \mathrm{s}$ \\
& Temperature & $300 \mathrm{~K}$ \\
& Pressure & $386 \mathrm{kPa}$ \\
& Composition oxygen & $23.3 \mathrm{wt} \%$ \\
& & $0 \mathrm{wt} \%$ \\
\hline
\end{tabular}

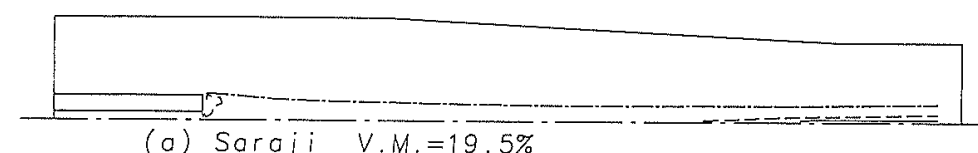

(a) Saraji V.M. $=19.5 \%$

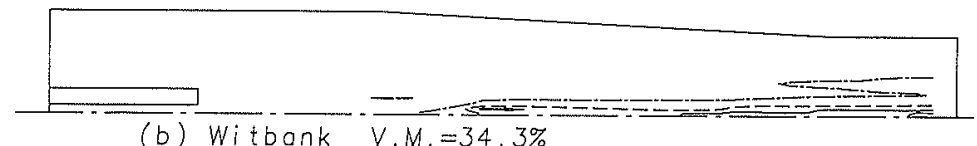

(b) Witbank V.M. $=34.3 \%$
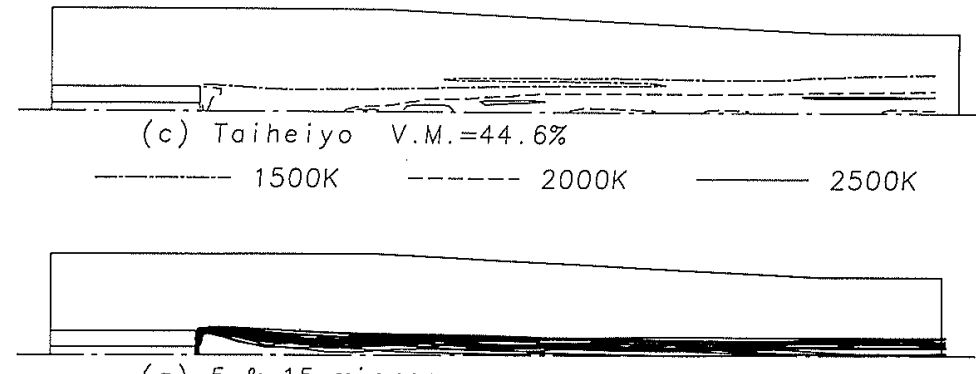

(a) 5 \& 15 micron

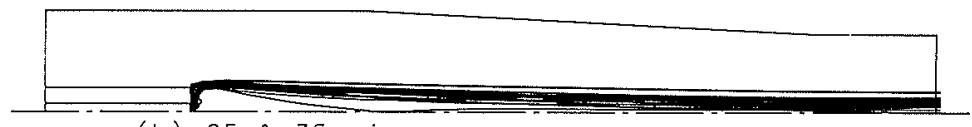

(b) $25 \& 35$ micron

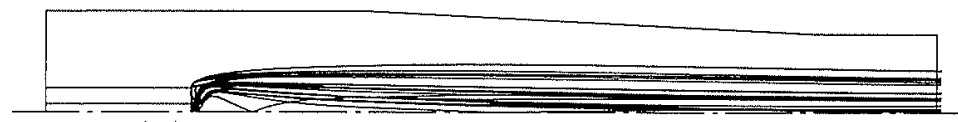

(c) $45 \& 55$ micron

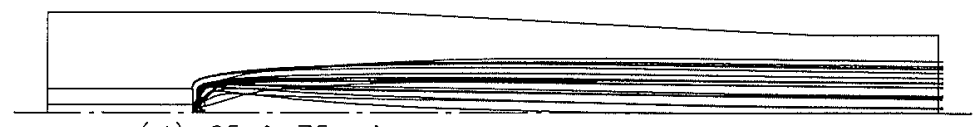

(d) $65 \& 75$ micron

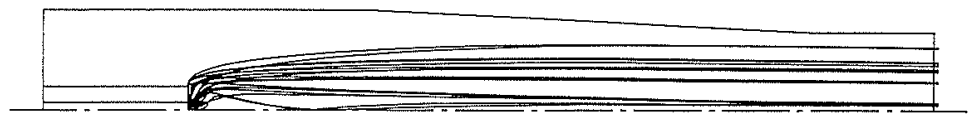

(e) 85 \& 95 micron

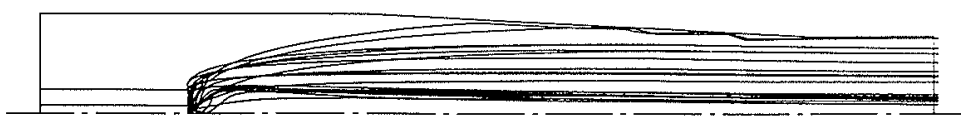

(d) 65 \& 75 micron

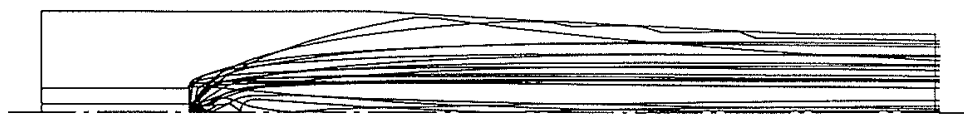

(e) $85 \& 95$ micron line also indicates the raceway boundary which means a dividing line of the value 0.5 between 0 assigned to the calculated cell where the particle motion does not occur and 1.0 to that where the particle motion occurs. According to the observation of raceway, after particles falling in front of tuyere are blown off in a little downward direction to the end of raceway, particles are divided into upward and downward streams along the raceway boundary and go back to the front of tuyere finally. At the region of particles moving backward, particles move more slowly than at the center of raceway because of the friction force between particles. The calculated results cannot represent raceway shapes exactly because of the rough grid arrangement for the raceway size, however, the depth and height of the particle flow pattern shows a good agreement with the experimental results.
Fig. 4.

Temperature distribution in the blowpipe.
Fig. 5 .

Calculated particle trajectories of Saraji coal in the blowpipe.
Fig. 6.

Calculated particle trajectories of Taiheiyo coal in the blowpipe. 


\subsection{Calculated Results of PC Combustion Model in the Blowpipe}

The calculated domain of the blowpipe is $800 \mathrm{~mm}$ length far from the tuyere tip and the lance tip is at the distance of $670 \mathrm{~mm}$ upstream from the tuyere tip as shown in Fig. 3. The blowpipe is gradually narrowed toward tuyere from 180 to $140 \mathrm{~mm}$ in internal diameter. The three kinds of coal are used in this study; Saraji, Witbank and Taiheiyo, having a different volatile matter contents from one another. The proximate and ultimate analyses of the coal samples are given in Table 6 and the calculation conditions in Table 7.

The effects of volatile matter content of coal on the calculated gas temperature distribution in the blowpipe are shown in Fig. 4. As the volatile matter content becomes high, the high temperature region appears near the lance. In all cases the high temperature region over $1500 \mathrm{~K}$ is extended nearly to the external radius of lance radially. The particle tajectories of Saraji coal is shown in Fig. 5 where ten representative particle trajectories are drawn for each diameter. The small particles under $30 \mu \mathrm{m}$ cannot disperse toward the radial direction while some particles over $60 \mu \mathrm{m}$ disperse in close to the inner wall of the blowpipe. This is because the large particle has a large initial momentum in the radial direction. As shown in Figs. 4 and 5, though the small particles mainly react in the blowpipe due to the small heat capacity, the burn-off at the blowpipe exit is less than $2 \%$.

Particle trajectories of Taiheiyo coal in diameter of 65 , $75,85,95 \mu \mathrm{m}$ are shown in Fig. 6. The mean residence time of $\mathrm{PC}$ is about $5 \mathrm{~ms}$ for any kind of coal. The burn-off of PC in the blowpipe is $5.8 \%$ for Saraji, $8.1 \%$ for Witbank and $16.4 \%$ for Taiheiyo coal, and appears to increase as the volatile matter content is high.

\subsection{Calculated Results of Combustion Model in the Coke Bed}

The estimation is carried out on the practical blast furnace having $14.8 \mathrm{~m}$ in bed diameter and 38 tuyere which is modeled as having the same horizontal crosssectional area per one tuyere in the two-dimen- sional calculation. The analytical region is then $7.4 \mathrm{~m}$ in width, $0.61 \mathrm{~m}$ in depth and $6.0 \mathrm{~m}$ in height with coke particles of $20 \mathrm{~mm}$ in diameter. The tuyere having 25 $\mathrm{mm}$ opening width is located at $1 \mathrm{~m}$ from the bottom of the furnace corresponding to the blow pipe outlet area. The inlet condition at the blowpipe without PCI is shown in Table 8 and is the same practical operating condition of productivity (iron formation rate per unit volume of blast furnace in a day) as one in the Sec. 3.2. The calculations are carried out in the case of condition with PCI (Witbank coal) and without PCI (all coke operation). In the case of operation with PCI, averaging values which is obtained from calculated results in the blowpipe combustion model are used for the gas phase inlet condition. The particle trajectory calculation in the coke bed is restarted from the final calculated result in the blow pipe combustion model.

Table 8. Calculation condition for the coke bed model without PCI.

\begin{tabular}{llc}
\hline Blast & Feed rate & $4.5 \mathrm{~kg} / \mathrm{s}$ \\
& Velocity at tuyere & $288 \mathrm{~m} / \mathrm{s}$ \\
& Temperature & $1318 \mathrm{~K}$ \\
& Pressure & $384 \mathrm{kPa}$ \\
& Composition oxygen & $23.5 \mathrm{wt} \%$ \\
& moisture & $3.6 \mathrm{wt} \%$ \\
\hline
\end{tabular}

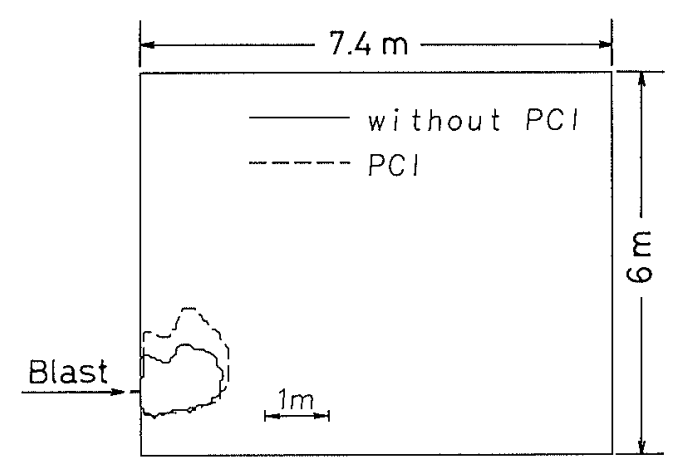

Fig. 7. Comparison of raceway shape with PCI and without PCI.
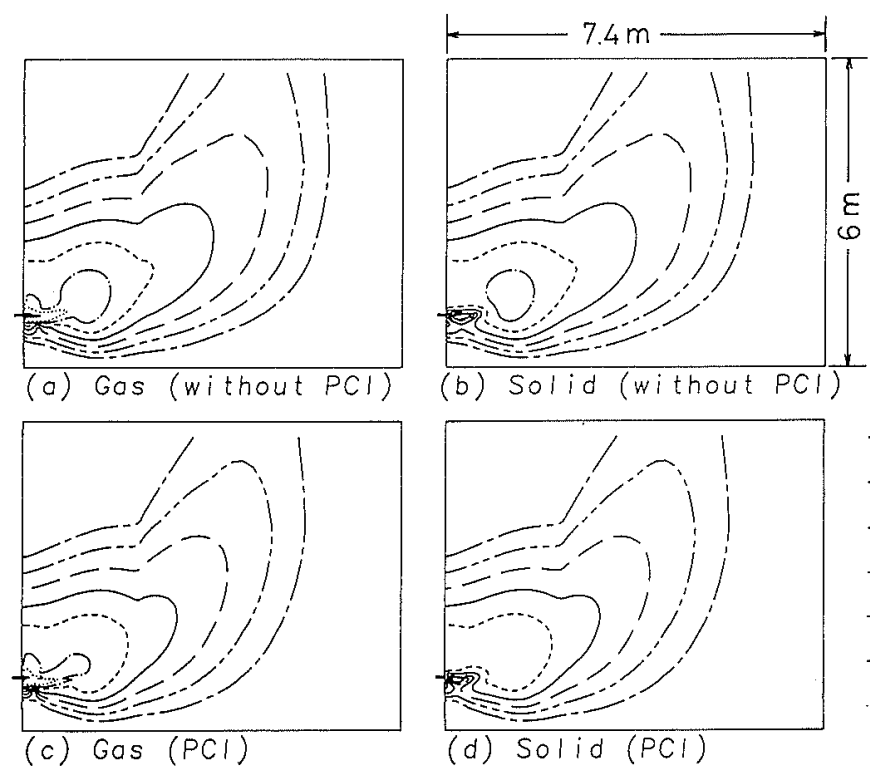

(d) Solid (PCl)

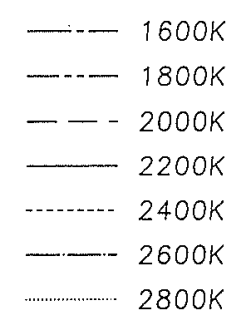

Fig. 8

Comparison of temperature distribution in the coke bed with PCI and without PCI 
Figure 7 shows the comparison of predicted raceway shape with PCI and without PCI. It is apparent that the coke particle moving region is large in the case with PCI compared with the case without PCI. This is because the rapid release of volatile matter from $\mathrm{PC}$ and gas phase combustion of volatiles and char combustion inside the raceway zone may cause the gas volume expansion which excludes the coke particles from the raceway zone.

Figure 8 shows the comparison of predicted gas and solid phase temperature distribution in the coke bed with and without PCI. Predicted results show the similar temperature distribution within the coke bed whether PC is injected or not. The gas temperature rises rapidly due to the combustion of coke or PC from the tuyere and finally reaches the maximum temperature in the raceway. After then the temperature gradually decreases as the gas disperses into the coke bed. The solid phase temperature takes the maximum values in both cases around the raceway boundary far from tuyere and the temperature gradually decreases in the same way as gas temperature. The maximum solid temperature with PCI operation is relatively lower than one without PCI operation and the high temperature region within the coke bed is also narrow compared with one without PCI. This is because the heat of coal combustion is smaller than one of coke and the rapid oxygen consumption occurs in PCI operation.

Figure 9 shows the predicted distribution of concentration of $\mathrm{CO}, \mathrm{CO}_{2}$ and $\mathrm{O}_{2}$ and of temperature in the gas phase on the tuyere axis. The oxygen supplied from tuyere is rapidly consumed by reaction with coke and $\mathrm{PC}$, and simultaneously $\mathrm{CO}_{2}$ concentration once increases. The maximum $\mathrm{CO}_{2}$ concentration appears near the maximum temperature region and its concentration decreases with increase in $\mathrm{CO}$. Although the distributions on the tuyere

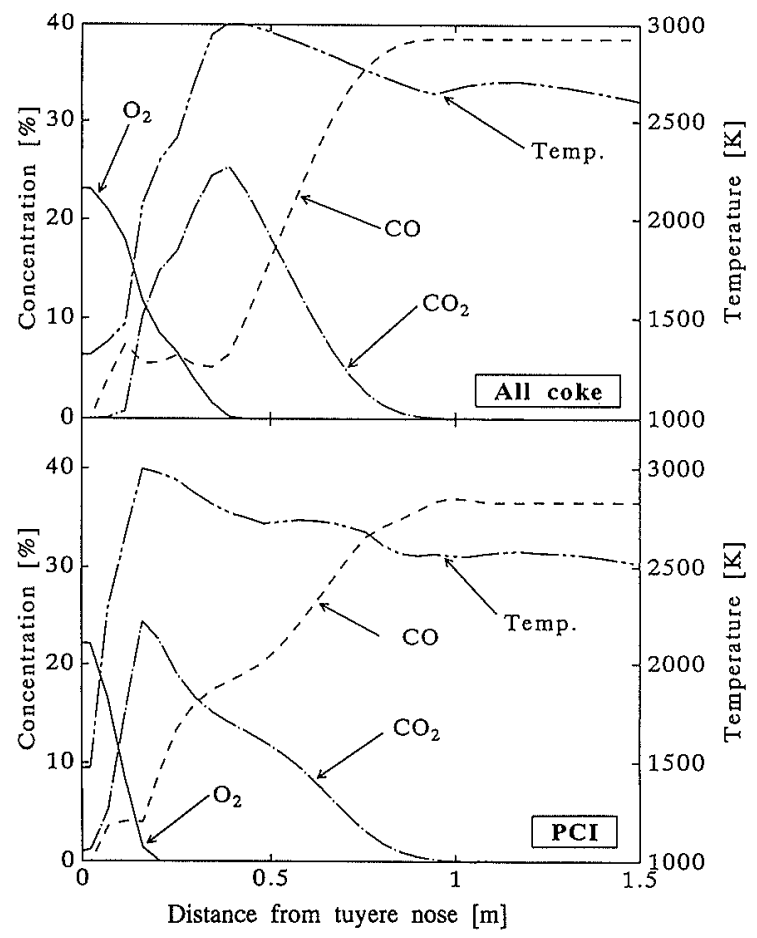

Fig. 9. Distributions of $\mathrm{CO}, \mathrm{CO}_{2}, \mathrm{O}_{2}$ concentration and gas temperature on the tuyere axis. axis above mentioned are similar in both operations with and without PCI, those in PC combustion move toward the tuyere because $\mathrm{PC}$ is burning in the raceway zone. The residence time in the raceway (from tuyere to the wall of raceway) is about $7 \mathrm{~ms}$ for any kind of coal and the total burn-off through the blowpipe and the raceway is $44.3 \%$ (Saraji), $73.9 \%$ (Witbank) and $96.2 \%$ (Taiheiyo), respectively. The estimated burn-off of PC calculated by $\mathrm{He}$ et $\mathrm{al}{ }^{3)}$ agrees with calculated results in this study, however these results underpredict the burn-off of PC compared with estimated results by Tamura et al. ${ }^{29)}$ As the kinetic parameter used in this study is measured in the general combustion chamber, further measurements to clarify the PC combustion mechanism at high intensity are necessary to predict the combustion behavior arround the raceway zone accurately.

\section{Conclusions}

A mathematical model for the transport phenomena in the packed bed of coke in front of blast furnace tuyere, which consists of two submodels (PC combustion model in the blowpipe and combustion model in the coke bed), has been described. This model can predict the raceway shape, the flow pattern of the gas and coke particles inside the raceway, PC combustion, heat and mass transfer and reactions in the coke bed simultaneously.

(1) The raceway shape and the flow pattern inside the raceway are in good agreement with experimental results in the cold tests of raceway.

(2) Predicted results of the blowpipe model show that the residence time of $\mathrm{PC}$ in the blowpipe is quite short and the burn-off of PC is very small especially in use of the low-volatile coal. On the other hand in use of the high-volatile coal, the dispersion of PC toward the radial direction increases and would probably cause the collision of PC against the tuyere wall and wear of tuyere.

(3) The comparison for the practical operation with PCI and without PCI is carried out in the coke bed model. When PC is injected into tuyere, more oxygen is consumed and higher rise of temperature appears at the region closer to the tuyere tip in the raceway and lower temperature is represented in the coke bed than those at the operation without PCI.

$\begin{aligned} & \text { Nomenclature } \\ & A_{p}: \text { surface area of PC particles }\left(\mathrm{m}^{2}\right) \\ & A_{b}: \text { specific surface area of coke bed }\left(\mathrm{m}^{-1}\right) \\ & C_{D_{p}}: \text { drag coefficient between a single particle and gas } \\ &(-) \\ & C_{p}: \text { specific heat }(\mathrm{J} / \mathrm{kg} \mathrm{K}) \\ & d: \text { particle diameter }(\mathrm{m}) \\ & D_{e}: \text { effective diffusivity }(\mathrm{kg} / \mathrm{m} \mathrm{s}) \\ & g: \text { gravitational acceleration }\left(\mathrm{m} / \mathrm{s}^{2}\right) \\ & h: \text { enthalpy }(\mathrm{J} / \mathrm{kg}) \\ & h_{c}: \text { convective heat transfer coefficient }\left(\mathrm{W} / \mathrm{m}^{2} \mathrm{~K}\right) \\ & h_{d}: \text { bed depth }(\mathrm{m}) \\ & I: \text { radiative heat flux }\left(\mathrm{W} / \mathrm{m}^{2}\right) \\ & K_{a}: \text { ratio of horizontal powder pressure to vertical } \\ & \text { one at dynamic state }(-) \\ & k_{c}: \text { rate constant of heterogeneous reaction }(\mathrm{kg} / \mathrm{s})\end{aligned}$


$k_{d}:$ mass transfer coefficient $\left(\mathrm{kg} / \mathrm{m}^{2} \mathrm{~s}\right)$

$k_{s}$ : rate constant of overall reaction $\left(\mathrm{kg} / \mathrm{m}^{2} \mathrm{~s}\right)$

$k_{v}$ : rate constant of devolatilization $\left(\mathrm{s}^{-1}\right)$

$P$ : pressure $(\mathrm{Pa})$

$Q:$ reaction heat $(\mathrm{J} / \mathrm{kg})$ or heat transfer rate $(\mathrm{W})$

$R$ : reaction rate $(\mathrm{kg} / \mathrm{s})$

$T:$ temperature $(\mathrm{K})$

$U, V:$ gas or packed particle velocity $(\mathrm{m} / \mathrm{s})$

$u_{p}, v_{p}:$ PC particle velocity $(\mathrm{m} / \mathrm{s})$

$w$ : weight $(\mathrm{kg})$

Greek symbols

$\varepsilon_{i}:$ voidage (一) $(i=$ bed, gas $)$

$\eta_{i}$ : effectiveness factor of catalyst $(-)$

$\kappa_{p}$ : absorption coefficient $\left(\mathrm{m}^{-1}\right)$

$\lambda:$ thermal conductivity $(\mathrm{W} / \mathrm{m} \mathrm{K})$

$\mu$ : viscosity (Pa s)

$\mu_{w}$ : dynamic friction factor between wall and particle $(-)$

$\rho:$ density $\left(\mathrm{kg} / \mathrm{m}^{3}\right)$

$\rho_{N}:$ number density $\left(\mathrm{m}^{-3}\right)$

$\psi_{c}:$ shape factor $(-)$

$\theta_{i}:$ internal friction angle (rad)

Subscripts

$b$ : bed

$c$ : char

e, eff: effective

$f u$ : fuel

$g:$ gas

$j:$ chemical species

$o x$ : oxidizer

$p:$ pulverized coal particle

$v$ : volatile matter

\section{REFERENCES}

1) M. Matsuura, H. Mitsufuji, T. Furukawa and Y. Ohno: $C A M P$ ISIJ, 3 (1990), 82.

2) M. Kuwabara, Y. Hsieh and I. Muchi: Tetsu-to-Hagané, 66 (1980), 1918

3) J. He, M. Kuwabara and I. Muchi: Tetsu-to-Hagané, 72 (1986),
1847.

4) J. Yagi, K. Takeda and Y. Ohmori: Trans. Iron Steel Inst. Jpn., 22 (1982), 82.

5) T. Sugiyama and M. Sugata: Seitetsu Kenkyu, 325 (1987), 34.

6) M. Kuwabara, S. Takane, K. Sekido and I. Muchi: Tetsu-toHagané, 77 (1991), 1593.

7) H. Nogami, T. Miura and S. Ohtani: 26th Symp. Combust. Jpn./The Combust. Inst. Jpn., (1988), 221.

8) S. V. Patankar: Numerical Heat Transfer and Fluid flow, McGraw-Hill, New York, (1980), 113.

9) M. Sato, J. Fukai, T. Miura and S. Ohtani: Coal Combustion, ed. by J. Feng, Hemisphere, New York, (1988), 215.

10) H. Kobayashi, J. B. Howard and A. F. Sarofim: 16th Symp. (Int.) Combust./The Combust. Inst., (1976), 411.

11) S. K. Ubhayakar, D. B. Stickler, C. W. von Rosenberg Jr. and R. E. Gannon: 16th Symp. (Int.) Combust./The Combust. Inst., (1976), 427.

12) J. M. Bergess, A. S. Jamaluddin, M. J. McCarthy, J. G. Mathieson, S. Nomura, J. S. Truelove and T. F. Wall: Proc. Joint Symp. of ISIJ and AIMM, Tokyo, (1983), 129.

13) M. A. Field: Combustion and Flame, 13 (1982), 237.

14) M. M. Bawm and P. J. Street: Combust. Sci. Tech., 3 (1971), 3.

15) R. M. Clift, J. R. Grace and M. E. Weber: Bubble, Drop and Particles, Academic Press, New York, (1978), 97.

16) C. T. Crowe, M. P. Sharma and D. E. Stock: J. Fluid Eng., 99 (1977), 325.

17) B. F. Magnussen, B. H. Hjertager, J. G. Olsen and D. Bhaduri: 17th Symp. (Int.) Combust./The Combust. Inst., (1979), 1383.

18) J. B. Howard, G. C. Williams and D. H. Fine: 14th Symp. (Int.) Combust./The Combust. Inst., (1970), 975.

19) M. A. Field, D. W. Gill, B. B. Morgan and P. G. W. Hawksley: Combustion of Pulverized Coal, Chenery \& Sons Ltd., Leatherhed, (1967), 189.

20) G. Heynert and J. Williams: Stahl Eisen, 79 (1959), 1545.

21) J. R. Arthur: Combustion of Pulverized Coal, Chenery \& Sons Ltd., Leatherhed, (1967), 201.

22) C. L. de Ligny: Chem. Eng. Sci., 25 (1970), 1177.

23) D. J. Gunn and C. Pryce: Trans. Inst. Chem. Eng., 47 (1969), T341.

24) D. Kunii and J. M. Smith: AIChE J., 6 (1960), 97.

25) W. E. Ranz: Chem. Eng. Prog., 48 (1952), 217

26) S. Ergun: Chem. Eng. Prog., 48 (1952), 89

27) C. Y.Wen and Y. H. Yu: Chem. Eng. Prog. Symp. Ser., 67 (1966), 100.

28) Kagaku-Kogaku-Binran, 5th ed. Maruzen, Tokyo, (1988), 868.

29) K. Tamura, H. Ueno, K. Yamaguchi, M. Sugata, S. Amano and K. Yamaguchi: Tetsu-to-Hagané, 77 (1991), 775. 